Ciencia y Salud, Vol. IV, No. 1, enero-abril, 2020 •ISSN (impreso): 2613-8816 • ISSN (en línea): 2613-8824

DOI: https://doi.org/10.22206/cysa.2020.v4i1.pp3-3

\title{
EDITORIAL \\ LAS ENFERMEDADES CRÓNICAS NO TRANSMISIBLES
}

Cómo citar: Morla E. Editorial las enfermedades crónicas no transmisibles. cysa [Internet]. 3 de marzo de 2020 [citado 4 de marzo de 2020];4(1):3-. Disponible en: https://revistas.intec.edu.do/index.php/cisa/article/view/1673

Las enfermedades crónicas no transmisibles engloban un grupo de enfermedades responsables de más del $50 \%$ de las muertes en muchos países y, además, de fallecimientos en edades tempranas.

Las principales enfermedades crónicas no transmisibles (ECNT) son la diabetes mellitus, la enfermedad pulmonar crónica, los trastornos cardiovasculares y el cáncer. Estas suelen ser de evolución muy lenta.

Las ECNT representan una gran carga económica para el paciente, su familia y el Estado, llegando a absorber más del $60 \%$ del gasto en salud pública.

Las enfermedades están relacionadas con la situación socioeconómica de cada país, y aunque las ECNT son más evidentes en los países desarrollados, por un mejor acceso al sistema de salud, constituyen una realidad y un gran reto para los países subdesarrollados o en vías de lograrlo.

Dadas las implicaciones sociales y económicas que representan las ECNT, tanto para la población como para el Estado, hay programas para prevenirlas o detener su evolución, pues tienen factores de riesgos en común como la alimentación inadecuada, la vida sedentaria y el tabaquismo.

La educación para la salud que debe realizarse en el hogar, en los centros educativos y desde los ministerios de salud con programas adecuadamente preparados para estos fines resulta ser la clave fundamental para enfrentar las enfermedades crónicas no transmisibles.

Dr. Elbi Morla

Editor

Correo-e: elbi.morla@intec.edu.do 